\title{
Micropapillary Pattern
}

National Cancer Institute

\section{Source}

National Cancer Institute. Micropapillary Pattern. NCI Thesaurus. Code C36181.

A morphologic finding indicating the presence of an architectural pattern dominated by the presence of small papillary structures. 